\title{
When Should Diclofenac Be Given in Ambulatory Surgery: Preoperatively or Postoperatively?
}

\author{
Andrew Norris, FRCA, * Victor Un, FRCPC, * \\ Frances Chung, FRCPC, $\uparrow$ \\ Sivapathasundaram Thanamayooran, $\mathrm{MD},+$ \\ Alan Sandler, FRCPC, $\uparrow$ Joel Katz, PhD§
}

*Clinical Fellow

†Staff Anesthesiologist

†Research Assistant

\$Psychologist

Department of Anesthesia, Toronto Western Hospital, University of Toronto, Toronto, Ontario, Canada; Department of Psychology, Toronto General Hospital, Department of Anesthesia, Toronto General Hospital, University of Toronto, Toronto, Ontario, Canada

Study Objective: To determine the optimum time of administration of diclofenac in patients undergoing ambulatory knee arthroscopy: either preoperatively or postoperatively. Design: Randomized, double-blind study.

Setting: Ambulatory surgical unit in a tertiany referral hospital.

Patients: 127 ASA physical status I and II patients undergoing ambulatory knee arthroscopy.

Interventions: Patients were randomized into three groups. The Preop group received 50 mg of potassium diclofenac orally 1 hour preoperatively and a placebo 30 minutes postoperatively. The Pre+postop group received $25 \mathrm{mg}$ of potassium diclofenac 1 hour preoperatively and $25 \mathrm{mg}$ diclofenac 30 minutes postoperatively. The Postop group received a placebo 1 hour before surgery and $50 \mathrm{mg}$ of potassium diclofenac 30 minutes postoperatively.

Measurements and Main Results: The Postop group received a placebo 1 hour preoperatively and $50 \mathrm{mg}$ of potassium diclofenac $30 \mathrm{~min}$ postoperatively. Postoperatively, patients used intravenous patient-controlled analgesia (PCA) with fentanyl. Total fentanyl consumption was recorded. During the recovery period, pain was assessed using a visual analog scale (VAS) at 30-minute intervals. Pain was assessed in both legs at rest, on flexion, and extension of the knee. There were no significant differences in pain scores either at rest or on movement of the operative knee among the Preop, Pretpostop, and Postop groups. The consumption of fentanyl via PCA showed no significant differences among the groups.

Conclusions: There is no difference in pain relief whether diclofenac is given preoperatively or postoperatively in patients undergoing unilateral ambulatory knee arthroscopy. Preoperative and postoperative treatment with diclofenac potassium is equally effective.

Keywords: Ambulatory anesthesia; ambulatory surgery; analgesia, postoperative; nonsteroidal antiinflammatory drugs. 


\section{Introduction}

Persistent postoperative pain remains a problem in ambulatory anesthesia, ${ }^{1}$ causing delays in discharge or unanticipated admission. Nonsteroidal antiinflammatory drugs (NSAIDs) are now commonly used as part of a balanced approach to the management of postoperative pain. They have been shown to exert an opioid-sparing effect in the postoperative period. ${ }^{2}$ Opioid-sparing may be particularly helpful in ambulatory surgical patients, in whom pain and nausea are common causes of delayed discharge. ${ }^{3}$

Despite numerous clinical investigations of the effect of NSAIDs on postoperative pain, the optimum time of administration, i.e., preoperatively versus postoperatively, has not been previously studied. The timing of administration is likely to affect the resulting analgesia by two mechanisms. Firstly, therapeutic concentrations should be achieved in the patient at the time of pain assessment. Secondly, preoperative administration may result in a preemptive analgesic effect, observable after the clinical duration of action of the NSAID.

Clinical investigations of preemptive analgesia have mainly involved opioid or local anesthetic based techniques. ${ }^{4-7}$ NSAIDs are known to exert some of their analgesic effects in the periphery by a reduction in the synthesis of inflammatory mediators resulting in an attenuation of peripheral sensitization. In the clinical setting, there have been four randomized, controlled trials examining the preemptive analgesic effects of NSAIDs. ${ }^{8-11}$ All have failed to demonstrate a benefit of preoperative administration over postoperative administration. This is perhaps not surprising given recent evidence that NSAIDs act not only in the periphery, but also in the central nervous system (CNS)..$^{12,13}$ None of the four negative studies of preemptive analgesia used a treatment group that received both preoperative and postoperative NSAIDs (i.e., a preoperative and a postoperative treatment group). It is possible that the lack of a significant difference between the groups reflects a predominantly central effect when given preoperatively and a peripheral effect when given postoperatively, with the result that no significant differences emerged between the groups.

In the present randomized, placebo-controlled study, we hypothesized that the combination of diclofenac administered before and after surgery would result in reduced postoperative pain and analgesic consumption when compared with its administration before or after surgery.

\section{Materials and Methods}

The study was approved by The Toronto Western Hospital Ethics Committee for Research on Human Subjects. Informed consent was obtained from patients (ASA physical status I and II) scheduled for ambulatory unilateral knee arthroscopies and intra-articular surgery. Exclusion criteria were: age greater than 65 or less than 18 years, active gastrointestinal (GI) ulcerative disease, history of reaction to NSAIDs, history of drug abuse, anticipated airway difficulty, hiatus hernia, morbid obesity, and analgesic use in the preceding 8 hours.

Preoperative and postoperative assessment was done by a research assistant who was blinded as to the group allocation. Patients were instructed preoperatively in the ambulatory surgery unit in the use of a $100-\mathrm{mm}$ visual analog scale (VAS) for pain, with endpoints labeled "no pain" and "worst pain imaginable," respectively. Baseline pain scores were then recorded for both knees at rest, on flexion, extension, and weight bearing. Patients were familiarized with the use of the patient-controlled analgesia (PCA) machine and instructed on completion of the postoperative questionnaire.

Patients were prospectively randomized into three groups by blocks of six using study numbers from random numbers table. The Preop group received $50 \mathrm{mg}$ of potassium diclofenac po 1 hour preoperatively and a placebo 30 minutes postoperatively. The Pre+postop group received $25 \mathrm{mg}$ of potassium diclofenac 1 hour preoperatively and $25 \mathrm{mg}$ diclofenac 30 minutes postoperatively. Postop group received a placebo 1 hour preoperatively and $50 \mathrm{mg}$ of potassium diclofenac 30 minutes postoperatively. Diclofenac and placebo (lactose) were reformulated into identical capsules by The Toronto Western Hospital pharmacy department.

A standardized anesthetic was used. Following intravenous (IV) induction using propofol 2 to $3 \mathrm{mg} / \mathrm{kg}$, a laryngeal mask airway (LMA) was inserted. Anesthesia was maintained with $70 \%$ nitrous oxide, $30 \%$ oxygen, and end-tidal isoflurane 0.5 to $2 \%$ titrated to requirement according to heart rate, blood pressure, and movement changes. All patients received $15 \mathrm{~mL} / \mathrm{kg}$ of $\mathrm{IV}$ normal saline in the operative period. No intraoperative opioids and no intraarticular local anesthetics or analgesics were used.

The postoperative capsule was given in phase 1 recovery as soon as airway reflexes returned approximately 30 minutes postoperatively. The PCA regime comprised a 20 $\mu \mathrm{g}$ fentanyl bolus with 5-minute lockout (Baxter PCA II pump, Baxter Healthcare Corporation, Deerfield, IL). Total fentanyl consumption was recorded. Pain was assessed using a VAS at 30-minute intervals during the recovery period. Pain was assessed in both legs at rest, on flexion, and extension of the knee. Recovery was assessed using the modified Postanesthesia Discharge Score (PADS) at 15-minute intervals until discharge. This system scores five recovery parameters (vital signs, ambulation, pain and nausea/vomiting, surgical bleeding, intake, and output) and scores each from 0 to $2 .{ }^{14}$ Patients were discharged when their PADS score reached 9 . Before discharge, patients were instructed again on completion of the postoperative questionnaires. All patients received sustained-release diclofenac $100 \mathrm{mg}$ orally (PO) on discharge. Analgesia at home consisted of standard dosing diclofenac $50 \mathrm{mg}$ three times a day for three days and acetaminophentcodeine when needed. Following discharge, patients completed daily questionnaires for three days. A 100-point verbal rating score (VRS) was used once daily to assess pain in both knees at rest, on flexion, extension, and weight bearing. A McGill Pain Question- 
Table 1. Demographic, Anesthetic, and Surgical Data

\begin{tabular}{lccc}
\hline & $\begin{array}{c}\text { Preop } \\
\text { Group } \\
(\mathbf{n}=\mathbf{4 0})\end{array}$ & $\begin{array}{c}\text { Pre+postop } \\
\text { Group } \\
(\mathbf{n}=\mathbf{4 3})\end{array}$ & $\begin{array}{c}\text { Postop } \\
\text { Group } \\
(\mathbf{n = 3 8})\end{array}$ \\
\hline Gender (M/F) & $35 / 5$ & $33 / 10$ & $27 / 11$ \\
Age (yrs) & $41 \pm 11$ & $31 \pm 12$ & $36 \pm 10$ \\
Height (cm) & $174 \pm 8$ & $174 \pm 8$ & $174 \pm 10$ \\
Weight (kg) & $84 \pm 16$ & $79 \pm 15$ & $80 \pm 15$ \\
$\begin{array}{l}\text { Duration of surgery } \\
\text { (min) }\end{array}$ & $38 \pm 11$ & $41 \pm 11$ & $42 \pm 15$ \\
Propofol (mg) & $304 \pm 74$ & $282 \pm 83$ & $293 \pm 84$ \\
\hline
\end{tabular}

Note: Values are expressed as means $\pm \mathrm{SD}$, where appropriate.

naire (MPQ) using 78 descriptors in 20 groups was also performed each day. Analgesic consumption was recorded. Functional recovery was assessed using an activity scoring scale $(1=$ able to stand with support, $2=$ able to stand without support, $3=$ walk with support, $4=$ walk without support, $5=$ stairs with support, $6=$ stairs without support). Completed questionnaires were returned to the anesthetic department when patients returned for surgical follow-up.

Estimation of the required number of patients was made according to a previous study on pain in ambulatory surgical patients. ${ }^{15}$ Thirty patients per group would be needed to detect a $30 \%$ reduction in dosage of fentanyl from $100 \mu \mathrm{g}$ with standard deviation of 50 , using a type 1 error rate of $5 \%$ and with $80 \%$ power.

For statistical analysis, repeat VAS for each patient was used to create an area under the curve (AUC) of pain against the time. The AUC, PCA fentanyl consumption, and the times taken to achieve a PADS of 9 were compared among the three groups using one-way analysis of variance (ANOVA). The MPQ was scored by number of words chosen (NWC) and by the sum of the rank scores (PRI). The resulting score, together with the functional scores and acetaminophen +codeine consumption, were compared among groups using the Kruskal-Wallis test. A $p$ value $<0.05$ was considered statistically significant.

\section{Results}

One hundred twenty-seven patients were recruited to the study. Six patients failed to complete the study. Four were withdrawn following protocol violation of administration of IV fentanyl at induction and two following administration of intraarticular bupivacaine, leaving a total of 121 patients (Preop group $=40$, Pre + postop group $=43$, Postop group $=38$ ). Ninety-six of 121 postoperative questionnaires were completed and returned (79\%). However, only 90 postoperative questionnaires could be tabulated, because six questionnaires were filled out incompletely.

There was no difference among the three groups with respect to demographic data, although the mean age in Preop group was found to be significantly greater than the Pre+post group and Postop group ( $p<0.01 ;$ Table 1$)$.
Table 2. Pain Scores and Fentanyl Use in the Postanesthesia Care Unit (PACU)

\begin{tabular}{|c|c|c|c|}
\hline & $\begin{array}{c}\text { Preop } \\
\text { Group } \\
(n=40)\end{array}$ & $\begin{array}{c}\text { Pre+Postop } \\
\text { Group } \\
(n=43)\end{array}$ & $\begin{array}{c}\text { Postop } \\
\text { Group } \\
(n=38)\end{array}$ \\
\hline \multicolumn{4}{|l|}{ VAS pain scales (mm) } \\
\hline $\begin{array}{l}\text { Preoperative baseline } \\
\text { (Knee at flexion) }\end{array}$ & $41 \pm 11$ & $33 \pm 12$ & $37 \pm 11$ \\
\hline Awake & $41 \pm 26$ & $48 \pm 27$ & $53 \pm 25$ \\
\hline $30 \mathrm{~min}$ & $41 \pm 24$ & $38 \pm 27$ & $48 \pm 24$ \\
\hline $60 \mathrm{~min}$ & $34 \pm 19$ & $27 \pm 22$ & $36 \pm 23$ \\
\hline $90 \mathrm{~min}$ & $33 \pm 21$ & $26 \pm 21$ & $30 \pm 21$ \\
\hline $120 \mathrm{~min}$ & $34 \pm 23$ & $24 \pm 19$ & $27 \pm 18$ \\
\hline \multicolumn{4}{|l|}{$\begin{array}{l}\text { Area under curve } \\
\text { (pain scale } \times \text { min) }\end{array}$} \\
\hline Knee at rest & $3833 \pm 2198$ & $3317 \pm 2308$ & $3896 \pm 2036$ \\
\hline Knee at flexion & $4323 \pm 2352$ & $4162 \pm 2634$ & $4618 \pm 2349$ \\
\hline Knee at extension & $3721 \pm 2479$ & $2825 \pm 2188$ & $3529 \pm 2223$ \\
\hline $\begin{array}{l}\text { PCA fentanyl dose } \\
(\mu g)\end{array}$ & $51 \pm 52$ & $75 \pm 80$ & $70 \pm 82$ \\
\hline $\begin{array}{l}\text { Time to achieve PADS } \\
\text { score of } 9 \text { (min) }\end{array}$ & $114 \pm 19$ & $118 \pm 18$ & $114 \pm 15$ \\
\hline
\end{tabular}

Note: Values are expressed as means $\pm \mathrm{SD}$.

VAS $=$ visual analog scale, $\mathrm{PCA}=$ patient-controlled analgesia, PADS $=$ postoperative anesthesia discharge score.

There was no difference among the three groups in the duration of surgery, the dosage of anesthetic drugs, or perioperative fluids. The majority of patients had some pain preoperatively, particularly on knee flexion. There was no significant difference in preoperative pain among the three groups. The pain VAS scales of the operative knee on flexion after surgery were also similar in the three groups. There was no significant difference among the groups in either the AUC of pain score against time or in the consumption of fentanyl via PCA during the recovery in the ambulatory surgical unit (Table 2). The percentage of patients who consumed the fentanyl in the Preop, the Pre+post, and the Postop groups were $73 \%, 79 \%$, and $84 \%(p=0.45)$, and the mean dosages were $65 \pm 44 \mu \mathrm{g}$, $93 \pm 69 \mu \mathrm{g}, 91 \pm 76 \mu \mathrm{g}(p=0.18)$, respectively. The percentage of successful fentanyl demand in three groups was $85 \%, 80 \%$, and $84 \%$, respectively $(p=0.58)$. There was no significant difference in the time taken to achieve a discharge score of 9 (Table 2).

At home, all three groups were similar in analgesic consumption and the functional score. For the McGill Pain Questionnaire, the number of words chosen and the pain rating index were not different among the three groups (Table 3).

\section{Discussion}

This study shows that preoperative administration of oral diclofenac potassium did not have any advantage in the reduction of postoperative pain, analgesic consumption, or improving functional recovery, in either the immediate or late postoperative periods, compared to the same dose of diclofenac given postoperatively. 
Table 3. Acetaminophen + codeine Consumption, McGill Pain Questionnaire (MPQ), and Functional Recovery Post Discharge

\begin{tabular}{|c|c|c|c|c|c|c|c|c|c|c|c|c|}
\hline \multirow[b]{2}{*}{ Postoperative days } & \multicolumn{4}{|c|}{ Preop Group $(\mathbf{n}=29)$} & \multicolumn{4}{|c|}{ Pretpostop Group $(n=30)$} & \multicolumn{4}{|c|}{ Postop Group $(\mathrm{n}=31)$} \\
\hline & 0 & $1^{\text {st }}$ & $2^{\text {nd }}$ & $3^{\text {rd }}$ & $\mathbf{0}$ & $1^{\text {st }}$ & $2^{\text {nd }}$ & $3^{\text {rd }}$ & $\mathbf{0}$ & $1^{\text {st }}$ & $2^{\text {nd }}$ & $3^{\text {rd }}$ \\
\hline $\begin{array}{l}\text { No. of acetaminophen } \\
\quad+\text { codeine }\end{array}$ & $2(0-8)$ & $2(0-12)$ & $0(0-12)$ & $0(0-8)$ & $2(0-6)$ & $2(0-8)$ & $0(0-6)$ & $0(0-4)$ & $2(0-6)$ & $2(0-8)$ & $1(0-8)$ & $1(0-3)$ \\
\hline \multicolumn{13}{|l|}{$\mathrm{MPQ}$} \\
\hline NWC & $N / A$ & $5(0-20)$ & $4(0-18)$ & $2(0-13)$ & $\mathrm{N} / \mathrm{A}$ & $5(1-20)$ & $3(0-12)$ & $2(0-14)$ & $N / A$ & $4(0-12)$ & $3(0-15)$ & $2(0-12)$ \\
\hline PRI & $N / A$ & $11(0-51)$ & $6(0-50)$ & $3(0-29)$ & $\mathrm{N} / \mathrm{A}$ & $10(0-44)$ & $6(0-24)$ & $4(0-33)$ & $\mathrm{N} / \mathrm{A}$ & $9(0-33)$ & $5(0-39)$ & $4(0-35)$ \\
\hline Functional score & $5(2-6)$ & $5(2-6)$ & $6(3-6)$ & $6(4-6)$ & $4(1-6)$ & $5(1-6)$ & $6(3-6)$ & $6(3-6)$ & $4(0-6)$ & $5(2-6)$ & $6(3-6)$ & $6(3-6)$ \\
\hline VAS pain scale $(\mathrm{mm})$ & & $45 \pm 18$ & $37 \pm 17$ & $31 \pm 19$ & & $48 \pm 18$ & $39 \pm 20$ & $28 \pm 17$ & & $46 \pm 23$ & $37 \pm 22$ & $29 \pm 18$ \\
\hline
\end{tabular}

Note: All data are expressed as medians (range) except VAS* (visual analog scale), which is expressed as means \pm SD. NWC $=$ number of words chosen, $\mathrm{N} / \mathrm{A}=$ not applicable, $\mathrm{PRI}=$ pain rating index.

NSAIDs achieve their suppressing hyperanalgesic effect by reducing the concentration of prostaglandins peripherally and centrally in different ways. ${ }^{16,17}$ Our results did not demonstrate a clinically effective preoperative analgesic effect of diclofenac. The circumstances of this study have several important differences from the ideal "preemptive" analgesic experiment. First, the concentration of diclofenac in plasma and synovial fluid is important to achieve the preemptive analgesic effect by the peripheral nervous system sensitization in response to tissue damage. The concentration of diclofenac in synovial fluids should be lower than plasma during the 40-min surgical procedure. The time to maximum drug concentration (Tmax) in synovial fluid is $60 \%$ to $70 \%$ of plasma concentration and develops after the Tmax in plasma (2-4 hours later) ${ }^{18}$ It is possible that adequate analgesic levels of diclofenac may not have been achieved at the time of surgery, even although the potassium diclofenac preparation was chosen because of its more rapid absorption than the more commonly used sodium salt. ${ }^{18}$ In addition, the patients' knees were irrigated using an automated system during the procedures. It is possible that this process of continuous irrigation might succeed in washing diclofenac either from the joint space itself or via concentration gradients from adjoining tissues during drug transition from the joint. ${ }^{19}$ Both reasons might result in the insufficient block of high-intensity noxious stimulation during the surgical procedure (first phase). ${ }^{20}$

Secondly, postoperative use of PCA fentanyl for highintensity noxious stimulation blurred pain intensity. Therefore, the statistically significance in VAS of pain would not be expected, and the result in this study proved it. The sample size is enough to detect the $30 \%$ difference in mean consumption of fentanyl among the Preop group, Pre + postop, and Postop groups. Unfortunately, the large deviation in fentanyl consumption made it difficult to detect the difference. There are several reasons for this finding: first of all, the fentanyl usage is significantly influenced by subjective factors in terms of mood, anxiety, expectations of recovery, perception of support, and expectation of pain relief. Secondly, changes in VAS score counterbalances changes of consumption of fentanyl resulted in failing to reach the difference. Finally, the mild to moderate intensity of postoperative pain in this proce- dure may be the other reason for insufficient difference of fentanyl consumption among three groups. ${ }^{90}$

Finally, the central actions of diclofenac may obscure its inhibition of peripheral afferent discharge because diclofenac can cross the blood-brain barrier ${ }^{21}$ and the central action is effective whether administered before or after the noxious stimulus. ${ }^{22}$ In a study of gynecological patients who underwent abdominal hysterectomy, the combination of extradural block and diclofenac suppository given before operation did not show a preoperative analgesic effect. ${ }^{23}$ The local anesthetic block and the CNS effect of diclofenac might have masked the preemptive analgesic effect of diclofenac.

In conclusion, this study shows that there is no difference in pain relief or need for supplemental opioid analgesics whether diclofenac is given preoperatively or postoperatively in patients undergoing unilateral ambulatory knee arthroscopy. It failed to demonstrate any additional benefit of pretreatment versus posttreatment with potassium diclofenac. Preoperative or postoperative treatment with diclofenac potassium is equally effective.

\section{References}

1. Fortier J, Chung F, Su J: Unanticipated admission after ambulatory surgery-a prospective study. Can J Anaesth 1998; 45:612-9.

2. Dunn TJ Clark VA, Jones G: Preoperative oral naproxen for pain relief after day-case laparoscopic sterilization. Br J Ancesth 1995; 75:12-4.

3. Chung F: Recovery pattern and home-readiness after ambulatory surgery. Anesth Analg 1995;80:896-902.

4. Katz J, Kavanagh BP, Sandler AN, et al: Preemptive analgesia. Clinical evidence of neuroplasticity contributing to postoperative pain. Anesthesiology 1992;77:439-46.

5. Katz J, Clairoux M, Kavanagh BP, et al: Pre-emptive lumbar epidural anaesthesia reduces postoperative pain and patientcontrolled morphine consumption after lower abdominal surgery. Pain 1994;59:395-403.

6. Gottschalk A, Smith DS, Jobes DR, et al: Preemptive epidural analgesia and recovery from radical prostatectomy: a randomized controlled trial. JAMA 1998;279:1076-82.

7. Katz J, Clairous M, Redahan C, et al: High dose alfentanil pre-empts pain after abdominal hysterectomy. Pain 1996;68:109_ 18. 
8. Flath RK, Hicks ML, Dionne RA, Pelleu GB Jr; Pain suppression after pulpectomy with preoperative Iluribiprofen. $J$ Endodont 1987;13:339-47.

9. Sisk AL, Mosley RO, Martin RP: Comparison of preoperative and postoperative diflunisal for suppression of postoperative pain. J Oral Maxillofac Surg 1989;47:464-8.

10. Sisk AL, Grover BJ: A comparison of preoperative and postoperative naproxen sodium for suppression of postoperative pain. J Oral Maxillofac Surg 1990;48:674-8.

11. Gustafsson I, Nystrom E, Quiding H: Effect of preoperative paracetamol on pain after oral surgery. Eur J Clin Pharmacol $1983 ; 24: 63-5$.

12. Malmberg AB, Yaksh TL: Antinociceptive actions of spinal nonsteroidal anti-inflammatory agents on the formalin tests in the rat. J Pharmacol Exp Ther 1992;263:136-46.

13. Eisenach JC: Aspirin, the miracle drug: spinally, too? Anesthesiology 1993;79:211-3.

14. Chung $\mathrm{F}$, Chan VWS, Ong D: A post-anesthetic discharge scoring system for home readiness after ambulatory surgery. J Clin Anesih $1995 ; 7 ; 500-6$.

15. Chung F, Ritchie E, Su J: Postoperative pain in ambulatory surgery. Anesth Analg 1997;85:808-16.
16. McCormack K: Non-steroidal anti-inflammatory drugs and spinal nociceptive processing. Pain 1994;59:9-43.

17. Woolf CJ, Chong MS: Preemptive analgesia-treating postoperative pain by preventing the establishment of central sensitization. Anesth Analg 1993;77:362-79.

18. Davies NM, Anderson KE: Clinical pharmacokinetics of diclofenac. Therapeutic insights and pitfalls. Clin Pharmacokinet 1997;33: $184-213$.

19. Elmquist WF, Chan KK, Sawchuk RJ: Transsynovial drug distribution: snyovial mean transit time of diclofenac and other nonsteroidal antiinflammatory drugs. Pharm Rese 1994;11:1689-97.

20. Kissin I: Preemptive analgesia - why its effect is not always obvious. Anesthesiology 1996;84:1015-9.

21. Zecca L, Ferrario P, Costi P: Determination of diclofenac and its metabolites in plasma and cerebrospinal fluid by high-performance liquid chromatography with electrochemical detection. J Chromalogr 1991;567:425-32.

22. Hudspith MJ: Pre-emptive analgesia with NSAID-what does it achieve? Br J Anaesth 1996;77:128-32.

23. Wuolijoki E, Oikarinen VJ, Ylipaavalniemi P, Hampf G, Tolvanen M: Effective postoperative pain control by preoperative injection of diclofenac. Eur.J Clin Pharmacol 1987;32:249-52. 